\title{
Changes in practice patterns in Japan from before to after JSDT 2013 guidelines on hemodialysis prescriptions: results from the JDOPPS
}

Tadashi Tomo ${ }^{1 *}$, Maria Larkina ${ }^{2,3}$, Ayumi Shintani ${ }^{4}$, Tomonari Ogawa ${ }^{5}$, Bruce M. Robinson ${ }^{2}$, Brian Bieber ${ }^{2}$, Lisa Henn² and Ronald L. Pisoni ${ }^{2}$

\begin{abstract}
Background: The Japanese Society for Dialysis Therapy (JSDT) published in 2013 inaugural hemodialysis (HD) guidelines. Specific targets include 1.4 for single-pool Kt/N (spKt/N) with a minimum dose of 1.2, minimum dialysis session length of 4 hours, minimum blood flow rate (BFR) of $200 \mathrm{~mL} / \mathrm{min}$, fluid removal rate no more than $15 \mathrm{~mL} / \mathrm{kg} / \mathrm{hr}$, and hemodiafiltration (HDF) therapy for certain identified symptoms. We evaluated the effect of these guidelines on actual practice in the years spanning 2005 - 2018.
\end{abstract}

Methods: Analyses were carried out to describe trends in the above HD prescription practices from December 2005 to April 2013 (before guideline publication) to August 2018 based on prevalent patient cross-sections from approximately 60 randomly selected HD facilities participating in the Japan Dialysis Outcomes and Practice Patterns Study.

Results: From April 2006 to August 2017 continual rises occurred in mean spKt/N (from 1.35 to 1.49), and percent of patients having spKt/N>1.2 (71\% to 85\%). Mean BFR increased with time from $198.3 \mathrm{~mL} / \mathrm{min}$ (April 2006) to $218.4 \mathrm{~mL} /$ min (August 2017), along with percent of patients with BFR $>200 \mathrm{ml} / \mathrm{min}$ (65\% to 85\%). HDF use increased slightly from 6\% (April 2006 and August 2009) to 8\% by April 2013, but increased greatly thereafter to 23\% by August 2017. In contrast, mean HD treatment time showed little change from 2006-2017, whereas mean UFR declined from 11.3 in 2006 to $8.4 \mathrm{~mL} / \mathrm{Kg} / \mathrm{hour}$ in 2017.

Conclusions: From 2006 - 2018 Japanese HD patients experienced marked improvement in reaching the spKt/N target specified by the 2013 JSDT guidelines. This may have been due to moderate increase in mean BFR even though mean HD session length did not change much. In addition, HDF use increased dramatically in this time period. Other HD delivery changes during this time, such as increased use of super high flux dialyzers, also merit study. While we cannot definitively conclude a causal relationship between the publication of the guidelines and the subsequent practice changes in Japan, those changes moved practice closer to the recommendations of the guidelines.

Keywords: Hemodialysis, guidelines, dialysis adequacy, Kt/N, hemodiafiltration, blood flow rate

*Correspondence: tomo@oita-u.ac.jp

${ }^{1}$ Clinical Engineering Research Center, Oita University, 5593

Idai-gaoka,1-1, Hasama-machi, Yufu-City, Oita, Japan

Full list of author information is available at the end of the article

\section{Background}

The National Cooperative Dialysis Study, an observational study, reported an association between dialysis dose and morbidity/mortality in hemodialysis (HD) patients [1]. Subsequently, several observational studies 
showed that higher dialysis dose and longer dialysis treatment time were associated with lower mortality rates. These studies confirmed that survival of HD patients is greatly influenced by dialysis prescription [2-5].

Based on these findings, the Kidney Disease Outcomes Quality Initiative (KDOQI) guidelines for hemodialysis adequacy were developed and recommended that single pool Kt/V should be 1.2 or higher (excluding residual kidney function), as a measure of dialysis dose for thrice weekly HD [6]. However, in the randomized clinical HEMO Study in 2002, higher dose hemodialysis, yielding an average single-pool Kt/V of 1.71, showed no survival benefit over lower dose hemodialysis at a singlepool Kt/V of 1.32 [HR=0.96; 95\% C.I. (0.84,1.10)] [7]. Nevertheless, subgroup analysis suggested that survival was increased for women in the higher dose Kt/V group [7, 8]. Subsequently, Port et al [9], using a much larger observational study dataset, similarly found increased survival for women at higher dose Kt/V levels. It should be noted that the hemodialysis treatment time in the HEMO Study was shorter and that the dialysis prescriptions in the HEMO Study were quite different from those in Japan and Europe. Therefore, it is difficult to apply these results to patients in Japan and Europe. Nonetheless, Kimata et al [10] based on Japan-DOPPS data from 1999-2011, observed lower Kt/V to be associated with elevated mortality among Japanese HD patients and more so among women $(\mathrm{HR}=1.13$ per 0.1 lower $\mathrm{Kt} / \mathrm{V}$, 95\% CI: $1.07-1.20)$ than among men $(\mathrm{HR}=1.06$ per 0.1 lower Kt/V, 95\% CI: 1.00-1.12).

Hemodialysis prescription varies greatly among countries. Considerable diversity in dialysis prescription is also reported in the Dialysis Outcomes and Practice Patterns Study (DOPPS) [11]. In Japan, dialysis patients typically receive a lower dialysis dose, with a dialysis treatment time of 4 hours and a blood flow rate of approximately $200 \mathrm{~mL} / \mathrm{min}$ [12]. It is important to consider that mortality of dialysis patients is greatly affected not only by dialysis dose but also by dialysis prescription factors including dialysis treatment time, blood flow rate, ultrafiltration rate, type of hemodialysis filter, and treatment modality [13]. In May 2013, the guidelines for hemodialysis prescription were published by the Japanese Society for Dialysis Therapy. The guidelines provide recommendations on dialysis-related factors including dose, treatment time, blood flow rate, and fluid removal rate. The recommendations are as follows: the minimum dialysis dose of single-pool Kt/V is 1.2 and the target dose is 1.4; the minimum blood flow rate is $200 \mathrm{~mL} / \mathrm{min}$; the minimum treatment time is 4 hours; and the fluid removal rate is 15 $\mathrm{mL} / \mathrm{kg} / \mathrm{hr}$ or lower. In addition, hemodiafiltration (HDF) is recommended for enhancing the removal of middle molecular-weight solutes (e.g., Beta-2-Microglobulin), for reducing inflammatory cytokines, and for alleviating patient symptoms such as poor appetite, itching, joint pain, and fatigue [14].

In this study, we investigated the impact of the 2013 Japanese Society for Dialysis Therapy Clinical Guideline for "Maintenance Hemodialysis: Hemodialysis Prescriptions" (hereafter referred to as the Guidelines) on hemodialysis prescription in Japan using the data of the Japan-DOPPS from 2005-2018 (DOPPS phase 3, 4, 5, and 6).

\section{Methods}

\section{Data source}

The DOPPS (http://www.dopps.org) is an international prospective cohort study of in-center HD patients randomly selected from a representative sample of dialysis facilities [11, 12, 15]. This analysis included data from 3,491 HD patients participating in Japan (JDOPPS) phases 3 (2005-2008), 4 (2009-2011), 5 (2012-2015), and 6 (2016-2018), for a total follow up time of 7,087 patient years. Data were reported based on patient medical records, using demographic variables and comorbidity reported at study entry in each study phase. In contrast, laboratory measurement values and medication prescriptions were based on data reported at study entry and updated every 4 months during study participation. All variables were collected using the same data collection tools for all JDOPPS participants. Study approval was obtained by a central institutional review board.

\section{Data Analysis}

Our analyses compared the achievement of dialysis adequacy guideline measures between two periods: before and after the May 2013 publication of the JSDT guidelines (GL). The studied GL measures were: single pool $\mathrm{Kt} / \mathrm{V}$ (spKt/V), blood flow rate (BFR), HD treatment time (TT), use of hemodiafiltration (HDF), and ultrafiltration rate (UFR).

Multivariable linear and generalized linear mixed models were used to assess the slope of the monthly changes in each studied GL measure (i.e., rate of change) that occurred before and after the May 2013 JSDT guideline publication. These models were adjusted for potential confounders including age, sex, time on dialysis, use of HDF (except when HDF use was the outcome), and 13 comorbid factors (diabetes mellitus, cerebrovascular accident (CVA), congestive heart failure, peripheral vascular disease, coronary artery disease, hypertension, other cardiovascular (CV) diseases, recurrent cellulitis/ gangrene, cancer other than skin, gastrointestinal (GI) bleeding, lung disease, neurologic disease, and psychiatric disorder). Auto-regressive, order 1 covariance structure was used based on assessment of best model fit as 
assessed by the Akaike information criterion (AIC) [16] and Bayesian information criterion (BIC) [17], also known as the Schwarz information criterion, among structures that converged across all analyses using multivariable linear mixed models. For binary outcome variables, multivariable generalized estimating equation (GEE) regression models were applied in a manner similar to the above. Subgroup analyses were performed on the following samples stratified by: sex, age (less than vs $\geq 70$ years old), and blood flow rate (less than vs. $\geq 200$ $\mathrm{mL} / \mathrm{min}$ ). Standard descriptive statistics characterized the DOPPS patients included in the study at several cross sections, representing each study phase, during follow up (April 2006, August 2009, April 2013, and August 2017).

Any longitudinal patient measures collected during the 13 years of the study period were included in the slope models. Median (interquartile range) of patient follow up was $3.76(2.59,6.24)$ years and median number of records was $12(9,20)$. Median (IQR) number of outcome variables of interest was $12(8,19)$ for BFR, TT, and $\mathrm{HDF}$, and $11(7,19)$ for Kt/V, and UFR. Adjustment variables (age, time since start of dialysis, use of $\mathrm{HDF}$, and 13 comorbidities) were updated at the beginning of each study phase. The effect of time was assessed with a variable indicating months counting to or from the GP (May 2013), an indicator of period prior or post GP, and a cross-product term of the two. The model for the outcome of use of HDF was necessarily unadjusted for HDF. However, reimbursement for HDF changed in April 2012, and its use likely changed in response to this. Consequently, we included in the HDF outcome model an indicator variable representing observations before vs. after April 2012 to capture this external effect.

All analyses used SAS software, version 9.4 (SAS institute, Cary, NC).

\section{Results}

Table 1 shows the changes before (April 2006, August 2009, April 2013) and after (August 2017) publication of the JSDT Guidelines for dialysis adequacy. The mean spKt/V increased with time, from 1.35 (April 2006) to 1.40 (August 2009) and to 1.42 (April 2013), even before publication of the Guidelines. The value further increased to 1.49 after publication of the Guidelines

Table 1 Descriptive statistics by DOPPS phase

\begin{tabular}{|c|c|c|c|c|}
\hline Variable & $\begin{array}{l}\text { Phase } 3 \\
\text { April } 2006\end{array}$ & $\begin{array}{l}\text { Phase } 4 \\
\text { August } 2009\end{array}$ & $\begin{array}{l}\text { Phase } 5 \\
\text { April } 2013\end{array}$ & $\begin{array}{l}\text { Phase } 6 \\
\text { August } 2017\end{array}$ \\
\hline N & 1765 & 1633 & 1731 & 1753 \\
\hline Mean age, years & $62.5(12.5)$ & $64.6(12.1)$ & $65.2(12.2)$ & $65.4(11.8)$ \\
\hline Male, \% & $60 \%$ & $62 \%$ & $65 \%$ & $67 \%$ \\
\hline Mean years on dialysis & $8.2(7.1)$ & $8.3(7.5)$ & $7.3(7.6)$ & $7.1(8)$ \\
\hline Mean sp Kt/N & $1.35(0.27)$ & $1.40(0.28)$ & $1.42(0.28)$ & $1.49(0.29)$ \\
\hline $\mathrm{sp} \mathrm{Kt} / \mathrm{N} \geq 1.2, \%$ & $71 \%$ & $77 \%$ & $79 \%$ & $85 \%$ \\
\hline Mean dialysis treatment duration, minutes & $238.2(30.6)$ & $236.4(28.4)$ & $238.4(27.2)$ & $243.3(26.7)$ \\
\hline Mean utrafiltration rate, $\mathrm{mL} / \mathrm{kg} / \mathrm{hr}$ & $11.3(4.1)$ & $8.6(3.5)$ & $8.7(3.5)$ & $8.4(3.3)$ \\
\hline Mean blood flow rate, mL/min & $198.3(27)$ & $202.2(27.5)$ & $207.9(31.1)$ & $218.4(35.3)$ \\
\hline Blood flow rate $\geq 200 \mathrm{~mL} / \mathrm{min}, \%$ & $65 \%$ & $72 \%$ & $78 \%$ & $85 \%$ \\
\hline Hemodiafiltration use, \% & $6 \%$ & $6 \%$ & $8 \%$ & $23 \%$ \\
\hline \multicolumn{5}{|l|}{ Comorbidities, \% } \\
\hline Coronary heart disease & $41 \%$ & $33 \%$ & $24 \%$ & $25 \%$ \\
\hline Congestive heart failure & $25 \%$ & $21 \%$ & $16 \%$ & $16 \%$ \\
\hline Cerebrovascular disease & $13 \%$ & $15 \%$ & $11 \%$ & $17 \%$ \\
\hline Other cardiovascular disease & $32 \%$ & $32 \%$ & $21 \%$ & $21 \%$ \\
\hline Peripheral vascular disease & $17 \%$ & $20 \%$ & $13 \%$ & $12 \%$ \\
\hline Hypertension & $73 \%$ & $79 \%$ & $80 \%$ & $85 \%$ \\
\hline Diabetes & $32 \%$ & $35 \%$ & $40 \%$ & $43 \%$ \\
\hline Gastrointestinal bleeding & $4 \%$ & $5 \%$ & $4 \%$ & $2 \%$ \\
\hline Neurologic disease & $10 \%$ & $9 \%$ & $6 \%$ & $6 \%$ \\
\hline Psychiatric disorder & $3 \%$ & $6 \%$ & $4 \%$ & $3 \%$ \\
\hline Recurrent cellulitis & $4 \%$ & $5 \%$ & $3 \%$ & $3 \%$ \\
\hline Cancer, non-skin & $9 \%$ & $11 \%$ & $10 \%$ & $12 \%$ \\
\hline
\end{tabular}

Shown are mean values (standard deviation) or percent prevalence of the indicated characteristic 
(August 2017). The pre-publication slope for mean $\mathrm{spKt} / \mathrm{v}$ was $+0.01481 /$ month, and the post-publication slope for mean spKt/v was $+0.01781 /$ year, with this slope difference of 0.003 /year not being statistically significant $(95 \%$ C.I. [ $-0.0022,0.0082]$, Table 2$)$. The percentage of patients having a single pool Kt/V of $\geq 1.2$ also increased with time from $71 \%$ in April 2006, to 77\% in August 2009 and to $79 \%$ by April 2013 before publication of the Guidelines, while further increasing to $85 \%$ after publication of the Guidelines (Figure 1).
The percentage of patients with a blood flow rate of $\geq 200 \mathrm{~mL} / \mathrm{min}$ increased with time from $65 \%$ (April 2006) to $72 \%$ (August 2009) and to $78 \%$ (April 2013) before publication of the Guidelines, and further increased to $85 \%$ after publication of the Guidelines (Figure 2). In logistic models of the odds of patients having a blood flow rate $\geq 200 \mathrm{~mL} / \mathrm{min}$ vs. not over time, the pre-publication slope was +0.1191 units/year whereas the postpublication slope was 0.0682 units/year. Post/pre slope difference was -0.051 units/year (95\% C.I. [-0.0995,

Table 2 Pre- and post-publication slopes and 95\% confidence intervals for linear mixed regression models

\begin{tabular}{|c|c|c|c|}
\hline Outcome & $\begin{array}{l}\text { Pre-Publication slope, per year }(95 \% \\
\left.\text { C.I. }{ }^{\text {a }}\right)\end{array}$ & $\begin{array}{l}\text { Post-Publication slope, per year } \\
\left(95 \% \text { C.I. }{ }^{a}\right)\end{array}$ & Difference in slopes $\left(95 \%\right.$ C.I. $\left.^{a}\right)$ \\
\hline $\mathrm{sp} \mathrm{Kt} / \mathrm{N}$ & $0.0148(0.0126,0.0171)$ & $0.0178(0.0138,0.0218)$ & $0.0030(-0.0022,0.0082)$ \\
\hline Treatment Time (min) & $0.7008(0.4654,0.9361)$ & $1.0809(0.6968,1.4651)$ & $0.3802(-0.1337,0.8941)$ \\
\hline UFR (mL/Kg/hour) & $-0.3257(-0.3548,-0.2965)$ & $0.0106(-0.0471,0.0682)$ & $0.3362(0.2670,0.4055)$ \\
\hline Blood Flow Rate (ml/min) & $1.5762(1.3177,1.8347)$ & $1.9583(1.5557,2.3610)$ & $0.3821(-0.1610,0.9252)$ \\
\hline
\end{tabular}

Note: slope changes were adjusted for covariates as described in Methods

${ }^{a}$ C.I. Confidence Interval

In case-mix adjusted logistic regression mixed models of the odds of patients having spKt/V $\geq 1.2$ vs. not over time, the pre-publication slope was +0.109 units/year. By contrast, the post-publication slope was +0.1292 units/year, resulting in a slope difference of 0.02015 units/year (95\% C.I. [ $-0.0434,0.0837]$, Table 3). In a sensitivity analysis, when models were not adjusted for HDF use, the post-/pre-slope difference was seen to be larger at +0.0279 units/year (but did not achieve 0.05 statistical significance).

The mean blood flow rate increased with time from $198.3 \mathrm{~mL} / \mathrm{min}$ (April 2006) to $201.7 \mathrm{~mL} / \mathrm{min}$ (August 2009) and to $202.2 \mathrm{~mL} / \mathrm{min}$ (April 2013) before publication of the Guidelines, and further increased to 218.4 $\mathrm{mL} / \mathrm{min}$ after publication of the Guidelines (August 2017, Table 1). Regarding mean blood flow rates over time, the pre-publication slope was $+1.5762 \mathrm{~mL} / \mathrm{min}$ per year compared to the post-publication slope of $+1.9583 \mathrm{~mL} /$ min per year, with a difference of $0.3821 \mathrm{~mL} / \mathrm{min}$ per year (95\% C.I. [-0.1610, 0.9252]; Table 2).

\section{$-0.0022]$, Table 3)}

The mean treatment time showed very little change over time before publication of the Guidelines (238.4 minutes in April 2006, 236.4 minutes in August 2009, and 238.4 minutes in April 2013), but increased slightly after publication of the Guidelines to 243.3 minutes in August 2017 (Table 1). The mean pre-publication slope for treatment time was 0.7008 minutes/year; the post-publication slope was 1.081 minutes/year, and the post/pre slope difference was 0.3802 minutes/year (95\% C.I. [-0.1337, 0.8941 ], Table 2).

The mean ultrafiltration rate (UFR) decreased with time from $11.3 \mathrm{~mL} / \mathrm{kg} / \mathrm{hr}$ (April 2006) to $8.6 \mathrm{~mL} / \mathrm{kg} /$ $\mathrm{hr}$ (August 2009), rising slightly to $8.7 \mathrm{~mL} / \mathrm{kg} / \mathrm{hr}$ (April 2013) before publication of the Guidelines, and further decreased to $8.4 \mathrm{~mL} / \mathrm{kg} / \mathrm{hr}$ after publication of the Guidelines (August 2017, Table 1). The pre-publication slope for UFR was $-0.3257 \mathrm{ml} / \mathrm{kg} / \mathrm{hr} /$ year, compared to the post-publication slope of $0.0106 \mathrm{~mL} / \mathrm{kg} / \mathrm{hr} /$ year. The

Table 3 Pre- and post-publication slopes and 95\% confidence intervals for logistic mixed regression models

\begin{tabular}{|c|c|c|c|}
\hline Outcome & $\begin{array}{l}\text { Pre-Publication slope, per year } \\
\left(95 \% \text { C.I. }{ }^{\text {a }}\right)\end{array}$ & $\begin{array}{l}\text { Post-Publication slope, per year } \\
(95 \% \text { C.I. })\end{array}$ & $\begin{array}{l}\text { Difference in slopes } \\
\left(95 \% \text { C.I. }{ }^{\mathrm{a}}\right)\end{array}$ \\
\hline Odds of $s p \mathrm{Kt} / \mathrm{N} \geq 1.2$ & $0.1090(0.0854,0.1326)$ & $0.1292(0.0750,0.1833)$ & $0.0202(-0.0434,0.0837)$ \\
\hline Odds of blood flow $\geq 200$ & $0.1191(0.0970,0.1412)$ & $0.0682(0.0297,0.1067)$ & $-0.0509(-0.0995,-0.0022)$ \\
\hline Odds of hemodiafiltration use & $0.0173(-0.0289,0.0634)$ & $0.3255(0.2849,0.3660)$ & $0.3082(0.2423,0.3741)$ \\
\hline
\end{tabular}

Note: slope changes were adjusted for covariates as described in Methods

${ }^{a}$ C.I. Confidence Interval 

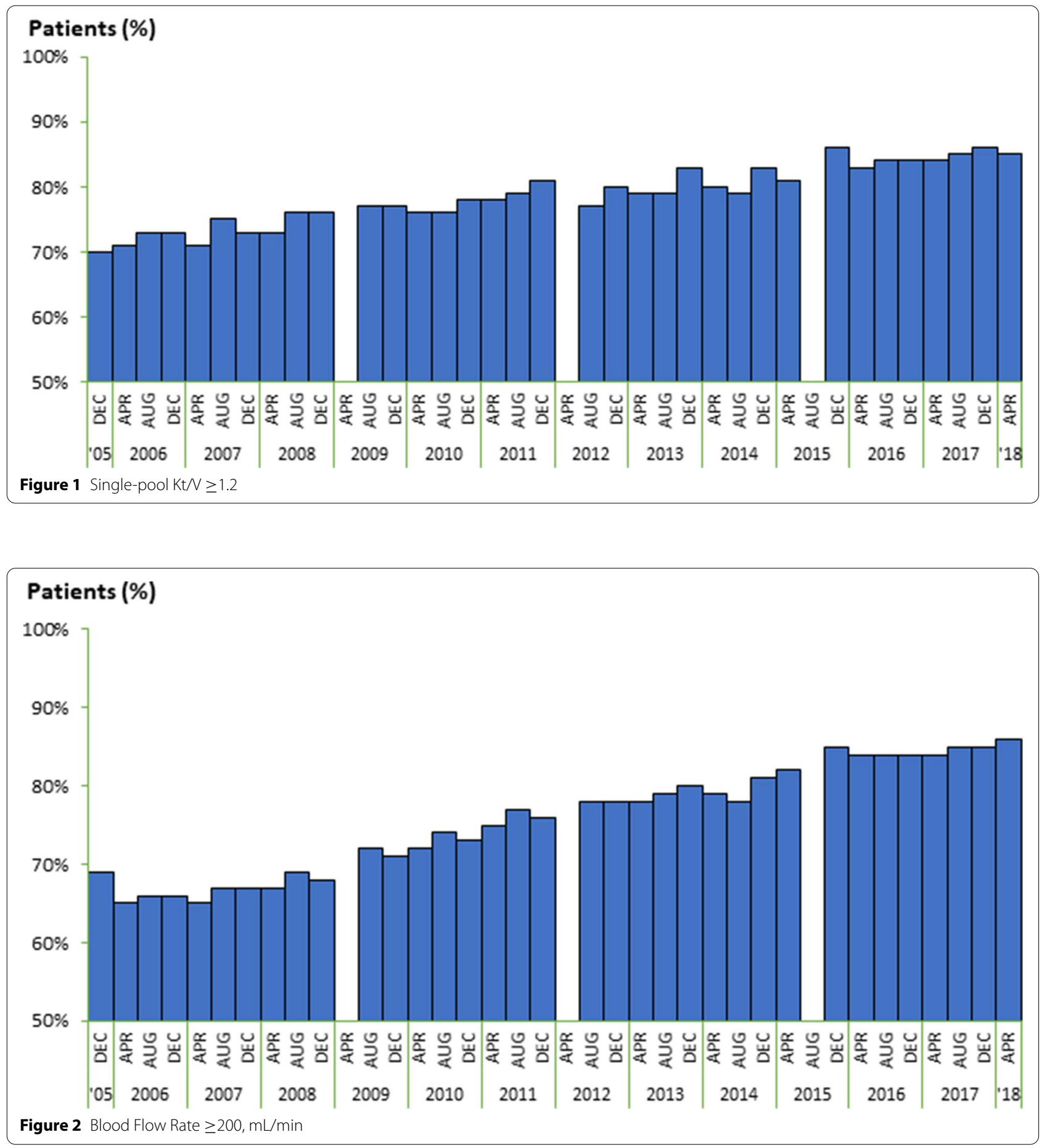

post/pre slope difference was $0.3362 \mathrm{ml} / \mathrm{kg} / \mathrm{hr} /$ year $(95 \%$ C.I. $[0.2670,0.4055])$.

Finally, the percentage of patients receiving HDF was 6\%, both in April 2006 and August 2009; which slightly increased to $8 \%$ by April 2013 and further increased to 23\% by August 2017 (Table 1). In logistic regression mixed models, the pre-publication slope for odds of HDF use was 0.0173 units/year compared to the postpublication slope of 0.3255 units/year. The difference between these two slopes was +0.3082 units/year $(95 \%$ C.I. [0.2423, 0.3741], Table 3). 


\section{Discussion}

Several observational studies have reported that dialysis prescription is associated with mortality [18-20]. These studies reported that the longer the dialysis treatment time, the lower the mortality rates. Furthermore, the HEMO trial found mortality rates to be lower for women when randomized to receive a higher dialysis dose $[7,9]$. It has also been reported that patients with a urea reduction rate of $\geq 65 \%$ had a lower mortality rate [21].

The DOPPS, a worldwide observational study, has yielded many significant findings. In particular, the DOPPS has reported that mortality was lower in dialysis patients in Japan than in Europe and the United States ${ }^{10}$ $, 11,15,19,20$. The DOPPS has also reported that many Japanese dialysis patients did not reach a single-pool Kt/V value of 1.2, although the KDOQI guidelines recommend this $\mathrm{Kt} / \mathrm{V}$ value as a minimum to be achieved $[6,10]$. The effect of the KDOQI guidelines on Japanese dialysis patients was considered to be less.

In this study, we investigated the effect of the Japanese Guidelines on dialysis prescription in Japanese patients using data from the Japan-DOPPS. We investigated the change in the indices for dialysis prescription from 2005 to 2018 (before and after publication of the Guidelines) in Japan-DOPPS participants. The mean single-pool $\mathrm{Kt} / \mathrm{V}$ increased with time from 1.35 (April 2006) to 1.40 (August 2009) and to 1.42 (April 2013) before publication of the Guidelines, and further increased to 1.49 after publication of the Guidelines (August 2017). In the linear mixed model, the pre-publication slope for $\mathrm{spKt} / \mathrm{v}$ was 0.0148 units/month versus 0.0178 units/ month for the post-publication slope, thus indicating an increase of $0.003 /$ month (95\% C.I. [ $-0.0022,0.0082]$ ) in the slope following the Guideline publication. Similarly, in case-mix adjusted analyses of the odds of of patients having an $\mathrm{spKt} / \mathrm{V} \geq 1.2$ vs. not over time revealed a prepublication slope of +0.109 units/month (OR 1.12) vs. +0.1292 units/month (OR 1.14) for the post-publication slope, indicating an increase of 0.0202 units/month (95\% C.I. $[-0.0434,0.0837)$ in the slope after the Guideline publication. Although the slope differences before vs. after the Guideline publication date were not statistically significant, a trend towards higher $\mathrm{spKt} / \mathrm{v}$ achievement after the Guideline publication was observed. The mean percentage of patients with a single pool Kt/V $\geq 1.2$ also increased with time from 71\% (April 2006) to 79\% (April 2013) before publication of the Guidelines, and to $85 \%$ after publication of the Guidelines. These results suggest that the pace of increase in $\mathrm{sp} \mathrm{Kt} / \mathrm{V}$ was accelerated after publication of the Guidelines.

The mean blood flow rate increased with time from $198.3 \mathrm{~mL} / \mathrm{min}$ (April 2006) to $202.2 \mathrm{~mL} / \mathrm{min}$ (August 2009) and to $207.9 \mathrm{~mL} / \mathrm{min}$ (April 2013) before publication of the Guidelines, and further increased to $218.4 \mathrm{~mL} / \mathrm{min}$ after publication of the Guidelines (August 2017). Mean blood flow rates increased over the entire study period, showing a pre-publication slope of $+1.5762 \mathrm{~mL} / \mathrm{min} / \mathrm{mo}$ vs. $+1.9583 \mathrm{~mL} / \mathrm{min} /$ mo for the post-publication slope, indicating a slope increase of 0.3821 (95\% C.I. [ $-0.1610,0.9252]$ ) after the Guideline publication date. However, case-mix adjusted analyses of the odds of patients having a blood flow rate $>200 \mathrm{~mL} / \mathrm{min}$ vs. not indicated a pre-publication slope of +0.1191 units/year (OR 1.13) compared to a slope of +0.0682 units/year (OR 1.07) after the Guideline publication year. This post- vs. pre-slope difference of -0.0509 units/month was statistically significant, with a $95 \%$ C.I. of $(-0.0995,-0.0022)$.

In Japan, the rate of arteriovenous fistula (AVF) use for hemodialysis vascular access is high. An association between higher AVF use and better survival rate has been reported [22-25]. Under the influence of the higher rate of AVF use, the mean blood flow rate in Japanese dialysis patients has been approximately $200 \mathrm{~mL} / \mathrm{min}$ for a long time [26]. However, the mean increased to $218.4 \mathrm{~mL} /$ min in August 2017. The possible reason for this is as follows. In 2012, online HDF was approved for insurance coverage, and the number of patients treated with online HDF increased because of the higher insurance reimbursement price. Patients treated with online HDF tend to have a higher blood flow rate compared with those treated with hemodialysis [27-29].

It is therefore suggested that the increase in the number of patients treated with online HDF beginning in 2012 affected the blood flow rate. In the registry of the Japanese Society for Dialysis Therapy, a similar trend in blood flow rate has been observed [30-32].

Treatment time did not show a marked increase during the period before publication of the Guidelines and showed a slight increase after publication of the Guidelines. The pre-publication slope for treatment time was $+0.7008 \mathrm{~min} /$ year, the post-publication slope was +1.081 $\mathrm{min} /$ year and the post- vs. pre-slope difference was +0.3802 . (95\% C.I. [ $-0.1337,0.8941])$. Thus, an increasing trend towards slightly longer treatment time was observed. The DOPPS has reported that treatment time was longer in hemodialysis patients in Japan than in the United States [19]. It is also reported that every 30-minute longer treatment time in an HD facility was associated with a $6 \%$ lower adjusted risk for death [19]. Despite the fact that dialysis patients are generally reluctant to extend their treatment time, the trend per year significantly increased after publication of the Guidelines, suggesting that the Guidelines had a significant influence on the same. 
There were no marked changes in the UFR, which is an important index for determining fluid removal. The UFR in the present study was relatively low, $11.3 \mathrm{~mL} /$ $\mathrm{kg} / \mathrm{hr}$ in 2009 and $8.6 \mathrm{~mL} / \mathrm{kg} / \mathrm{hr}$ in 2013, and thereafter decreasing slightly to $8.4 \mathrm{~mL} / \mathrm{kg} / \mathrm{hr}$ in 2017 . The Guidelines recommend that UFR be $15 \mathrm{~mL} / \mathrm{kg} / \mathrm{hr}$ or lower. The DOPPS reported that UFR $\leq 10 \mathrm{~mL} / \mathrm{kg} / \mathrm{hr}$ is associated with better survival [18]. Movilli et al. also recommended that UFR be $\leq 12 \mathrm{~mL} / \mathrm{kg} / \mathrm{hr}$ [33] and Flythe et al. recommended $<13 \mathrm{~mL} / \mathrm{kg} / \mathrm{hr}$ [34].

Recently, Wong et al reported trends towards lower UFR levels and lower interdialytic weight gain in the US, Canada, Europe, and Australia/New Zealand based on DOPPS data from 2002-2014 [35]. In the "Japanese Society for Dialysis Therapy Guidelines for Management of Cardiovascular Diseases in Patients on Chronic Hemodialysis," it is recommended that the amount of water removed per unit time should be mitigated to avoid a drop in blood pressure during dialysis, and prolongation of the duration of dialysis should be considered [36]. Although the UFR in Japanese dialysis patients had been low, it further decreased to $8.4 \mathrm{~mL} / \mathrm{kg} / \mathrm{hr}$ after publication of the Guidelines, suggesting an influence of the Guidelines.

The percent of patients treated with HDF was $6 \%$ in both April 2006 and August 2009; the value slightly increased to 8\% in April 2013 and further increased to 23\% in August 2017. The pre-publication slope for odds of patients prescribed HDF was +0.0173 units/year (OR $1.02)$ vs. the post-publication slope of +0.3255 units/ year (OR 1.38). Thus the slope in odds of HDF use markedly increased by +0.3082 units/year ( $95 \%$ C.I. [0.2423, $0.3741]$ ) following publication of the Guidelines. As mentioned earlier, the plausible reason for this is that online HDF was approved for insurance coverage in 2012. However, the percentage of patients treated with HDF only increased to $8 \%$ in April 2013 despite online HDF being added to the insurance coverage list in 2012. This might be due to the fact that the dialysis console for online HDF was still not in widespread use at that time due to more limited availability. The rapid increase in the percentage of patients treated with online HDF in 2017 was probably due to the much greater availability of this dialysis console in Japan by 2017.

Online haemodiafiltration (HDF) today represents the most advanced and innovative form of renal replacement therapy, and online HDF treatment is now widespread in many countries. There are several characteristics to note regarding Japanese online HDF. The first is the high use of the pre-dilution mode; the second is treatment at a relatively low blood flow rate compared with Europe; and the third is the typical use of a high performance membrane filter. These three characteristics are mutually related. The reason for the wide spread use of pre-dilution mode in online HDF is due to the low blood flow rate utilized in Japan. Furthermore, pre-dilution mode online HDF has the advantage of reducing albumin loss when using a high-performance membrane filter.

In Japan, online HDF is selected as the most advanced blood purification modality to eliminate uremic solutes similar in molecular weight to $\alpha 1-$ macroglobulin, but not for removing $\beta 2$-microglobulin. In JSDT Renal Registry data (2017), the mean removal rate was $60.7 \%$ for HD patients overall and $71.4 \%$ for HDF patients overall, indicating that HDF patients overall had a higher mean value than HD patients overall. Nevertheless, there was no marked difference in the pre-dialysis $\beta 2$-microglobulin levels between HD and online HDF patient groups [32].

Roumelioti et al [37] have also reported that various factors such as a blood purification mode, dialytic fluid flow rate, blood flow rate, and membrane materials of filters or dialyzers influence clearance of the $\beta 2$-microglobulin. In Japan, many kinds of dialyzers or filters of various membrane materials are used [32]; this factor may influence blood concentration levels of $\beta 2$-microglobulin.

However, removing solutes similar in size to $\alpha 1$-microglobulin results in greater loss of serum albumin. It is thought that uremic solutes around $\alpha 1-$ microglobulin in size can be safely and effectively removed while reducing albumin leak by using the predilution mode when performing online HDF. In the technical aspects, the lower blood flow rate used in Japan compared with that used in Europe may be suitable for pre-dilution mode online HDF using a high performance membrane filter in Japan [29-32, 38-40].

On the basis of these various factors (incentive in health insurance reimbursement, widespread availability of an HDF console machine, recommendations in the Guidelines, expectations for advanced modality, suitability in the technical aspects), the number of "online HDF" cases increased rapidly from 2013 - 2018.

Our study has several limitations, including its observational design. We investigated the impact of the Guidelines on dialysis prescription, but we could not exclude the influences of the following confounding factors. First, we could not eliminate the influence of the revision in the medical payment system. As is well known, there is a possibility that the selection of treatment modality is greatly influenced by insurance coverage. The impact of this factor might have been as great as that of the Guidelines. In addition, the blood flow rate might have been influenced by changes in treatment mode, which could be a confounding factor. 
Lastly, even though patients and facilities included in JDOPPS were randomly selected for participation, we cannot entirely exclude patient selection bias depending upon which facilities and patients consented to study participation. This can affect the generalizability of study findings to the extent of such a possible bias existing.

\section{Conclusions}

This study investigated the effect of the Japanese Society for Dialysis Therapy Clinical Guideline for "Maintenance Hemodialysis: Hemodialysis Prescriptions" published in 2013 on hemodialysis prescription in Japan using the data obtained from Japan-DOPPS. The results showed increases in several parameters for dialysis therapy including single-pool $\mathrm{Kt} / \mathrm{V}$, blood flow rate, treatment time, and HDF use after publication of the Guidelines, suggesting an influence of the Guidelines on dialysis prescription.

\begin{abstract}
Abbreviations
AIC: Akaike information criterion; AVF: Arteriovenous fistula; BIC: Bayesian information criterion; BFR: Blood flow rate; CV: Cardiovascular; CVA: Cerebrovascular accident; DOPPS: Dialysis Outcomes and Practice Patterns Study; GI: Gastrointestinal; GEE: Generalized estimating equation; GL: Guidelines; HDF: Hemodiafiltration; HD: Hemodialysis; KDOQI: Kidney Disease Outcomes Quality Initiative; spKt/N: Single-pool Kt/N; TT: Treatment time; UFR: Ultrafiltration rate.
\end{abstract}

\section{Acknowledgements}

We wish to express our appreciation to the J-DOPPS Steering Committee members for their support of this project. We are also very grateful to the study nurses, physicians, medical directors, and patients for their participation, and all the time and attention they have devoted to the J-DOPPS study in Japan. We also wish to thank Kyowa Kirin Corporation for its support of this specific investigation, and to the large consortium of funders supporing more broadly the DOPPS Program overall as indicated at www.dopps.org.

Jennifer McCready-Maynes, an employee of Arbor Research Collaborative for Health, provided editorial assistance for this paper.

\section{Authors' contributions}

1) to have made substantial contributions to the conception or design of the work: $L H, B B, T T, A S, T O, B R, R P .2$ ) the acquisition, analysis, or interpretation of data: $L H, M L, B B, T T, A S, T O, B R, R P .3)$ the creation of new software used in the work:. 4) have drafted the work or substantively revised it: $L H, B B, T T, A S, T O, B R$, RP. The author(s) read and approved the final manuscript.

\section{Funding}

Global support for the ongoing DOPPS Programs is provided without restriction on publications by a variety of funders. For details see https://www. dopps.org/AboutUs/Support.aspx. This manuscript was directly supported by Kyowa Kirin Corporation.

\section{Availability of data and materials}

The datasets used and/or analysed during the current study are available from the corresponding author on reasonable request.

\section{Declarations}

Ethics approval and consent to participate

Study approval was obtained from Tokyo Women's Medical University Ethics Committee in Japan. Study coordinators at each study facility obtained informed consent from all randomly selected patients. All methods were carried out in accordance with relevant guidelines and regulations.

\section{Consent for publication}

Not applicable

\section{Competing interests}

Brian Bieber, Lisa Henn, and Ronald L. Pisoni are employees of Arbor Research Collaborative for Health which administers the DOPPS. Bruce Robinson is an employee of Arbor Research Collaborative for Health, which administers the DOPPS Program. Dr Robinson has received consultancy fees or travel reimbursement from AstraZeneca, GlaxoSmithKline, and Kyowa Kirin Co., all paid directly to his institution of employment. Ayumi Shintani, Maria Larkina, Tomonari Ogawa,and Tadashi Tomo have no conflicts of interest to declare.

\section{Author details}

${ }^{1}$ Clinical Engineering Research Center, Oita University, 5593 Idai-gaoka,1-1, Hasama-machi, Yufu-City, Oita, Japan. ${ }^{2}$ Arbor Research Collaborative for Health, Ann Arbor, USA. ${ }^{3}$ Currently at Michigan Medicine, Department of Internal Medicine, Nephrology Division, University of Michigan, Ann Arbor, Michigan, USA. ${ }^{4}$ Department of Medical Statistics, Graduate School of Medicine Osaka City University, Osaka, Japan. ${ }^{5}$ Department of Nephrology and Blood Purification Center Saitama Medical Center, Medical University, Saitama, Japan.

Received: 22 June 2021 Accepted: 27 September 2021

Published online: 14 October 2021

\section{References}

1. Gotch FA, Sargent JA. A mechanistic analysis of the National Cooperative Dialysis Study (NCDS). Kidney Int. 1985;28:526-34.

2. Collins AJ, Ma JZ, Umen A, Keshaviah P. Urea index and other predictors of hemodialysis patient survival. Am J Kidney Dis. 1994;23:272-82.

3. Hakim RM, Breyer J, Ismail N, Schulman G. Effects of dose of dialysis on morbidity and mortality. Am J Kidney Dis. 1994;23:661-9.

4. Parker TF, Husni L, Huang W, Lew N, Lowrie EG. Survival of hemodialysis patients in the United States is improved with greater quantity of dialysis. Am J Kidney Dis. 1994;23:670-80.

5. Held PJ, Port FK, Wolfe RA, et al. The dose of hemodialysis and patient mortality. Kidney Int. 1996;50:550-6.

6. National Kidney Foundation. Clinical practice guidelinesfor hemodialysis adequacy. Am J Kidney Dis. 2006:48(Suppl 1):s12-47.

7. Eknoyan G, Beck GJ, Cheung AK, et al. Effect of dialysis dose and membrane flux in maintenance hemodialysis. N Engl J Med. 2002:347:2010-9.

8. Depner T, Daugirdas J, Greene T, et al. Dialysis dose and the effect of gender and body size on outcome in the HEMO Study. Kidney Int. 2004;65(4):1386-94

9. Port FK, Wolfe RA, Hulbert-Shearon TE, McCullough KP, Ashby VB, Held PJ. High dialysis dose is associated with lower mortality among women but not among men. Am J Kidney Dis. 2004;43(6):1014-23.

10. Kimata N, Karaboyas A, Bieber BA, et al. Gender, low Kt/N, and mortality in Japanese hemodialysis patients: opportunities for improvement through modifiable practices. Hemodial Int. 2014 Jul;18(3):596-606.

11. Robinson BM, Akizawa T, Jager KJ, Kerr PG, Saran R, Pisoni RL. Factors affecting outcomes in patients reaching end-stage kidney disease worldwide: differences in access to renal replacement therapy, modality use, and haemodialysis practices. Lancet. 2016;388:294-306.

12. Robinson BM, Bieber BA, Pisoni RL, Port FK. Dialysis Outcomes and Practice Patterns Study (DOPPS): Its Strengths, Limitations, and Role in Informing Practices and Policies. Clin J Am Soc Nephrol. 2012 Nov; 7(11):1897-905.

13. Locatelli F, Karaboyas A, Pisoni R, et al. Mortality risk in patients on hemodiafiltration versus hemodialysis: A 'real-world' comparison from the DOPPS. Neph Dial Transplant. 2018;33:683-9.

14. Watanabe Y, Kawanishi H, Suzuki K, et al. Japanese Society for Dialysis Therapy Japanese Society for Dialysis Therapy Clinical Guideline for "Maintenance Hemodialysis: Hemodialysis Prescriptions." Therapeutic Apheresis and Dialysis. 2015;19(Supplement 1):67-92. 
15. Goodkin DA, Young EW, Kurokawa K, Prütz KG, Levin NW. Mortality among hemodialysis patients in Europe, Japan, and the United States: case-mix effects. Am J Kidney Dis. 2004 Nov;44(5 Suppl 2):16-21.

16. Akaike $H$. A new look at the statistical model identification. IEEE Transactions on Automatic Control. 1974;19(6):716-23. https://doi.org/10.1109/ TAC.1974.1100705.

17. Schwarz GE. Estimating the dimension of a model. Annals of Statistics. 1978;6(2):461-4. https://doi.org/10.1214/aos/1176344136.

18. Shinzato T, Nakai S, Akiba T, et al. Survival in longterm haemodialysis patients:results from the annual survey of the Japanese Society for Dialysis Therapy. Nephrol Dial Transplant. 1997;12:884-8.

19. Saran R, Bragg-Gresham JL, Levin NW, et al. Longer treatment time and slower ultrafiltration in hemodialysis: Associations with reduced mortality in the DOPPS. Kidney Int. 2006;69:1222-8.

20. Tentori F, Zhang J, Li Y, et al. Longer dialysis session length is associated with better intermediate outcomes and survival among patients on in-center three times per week hemodialysis:results from the Dialysis Outcomes and Practice Patterns Study. (DOPPS). Nephrol Dial Transplant. 2012;27:4180-8.

21. Owen WF, Lew NL, Liu Y, Lowrie EG, Lazarus JM. The urea reduction ratio and serum albumin concentration as predictors of mortality in patients undergoing hemodialysis. N Engl J Med. 1993;329:1001-6.

22. Pisoni RL, Arrington CJ, Albert JM, et al. Facility hemodialysis vascular access use and mortality in countries participating in DOPPS: an instrumental variable analysis. Am J Kidney Dis. 2009;53(3):475-91.

23. Polkinghorne KR, McDonald SP, Atkins RC, Kerr PG. Vascular access and all-cause mortality: a propensity score analysis. J Am Soc Nephrol. 2004;15:477-86

24. Allon M, Daugirdas J, Depner TA, Greene T, Ornt D, Schwab SJ. Effect of change in vascular access on patient mortality in hemodialysis patients. Am J Kidney Dis. 2006:47(3):469-77.

25. Lacson E Jr, Wang W, Hakim RM, Teng M, Lazarus JM. Associates of mortality and hospitalization in hemodialysis:potentially actionable laboratory variables and vascular access. Am J Kidney Dis. 2009;53(1):79-90.

26. Pisoni RL, Zepel L, Fluck R, et al. International Differences in the Location and Use of Arteriovenous Accesses Created for Hemodialysis: Results From the Dialysis Outcomes and Practice Patterns Study (DOPPS). Am J Kidney Dis. 2018 Apr;71(4):469-78.

27. Maduell F, Broseta JJ, Rodas L, et al. Comparison of Solute Removal Properties Between High-Efficient Dialysis Modalities in Low Blood Flow Rate. Ther Apher Dial. 2020 Aug;24(4):387-92.

28. Kikuchi K, Hamano T, Wada A, Nakai S, Masakane I. Predilution online hemodiafiltration is associated with improved survival compared with hemodialysis. Kidney Inter. 2019;95:929-38.
29. Akizawa T, Koiwa F Clinical Expectation of Online Hemodiafiltration: A Japanese Perspective. Blood Purif. 2015;40(suppl 1):12-6.

30. Masakane I, Taniguchi M, Nakai S, Tsuchida K, Goto S, Wada A, Nakamoto H. Annual Dialysis Data Report 2015, JSDT Renal Data Registry. Ren Replace Ther. 2018;4(1):1-99.

31. Masakane I, Taniguchi M, Nakai S, et al. Annual Dialysis Data Report 2016, JSDT Renal Data Registry. Ren Replace Ther. 2018:4(45). https://doi.org/10. 1186/s41100-018-0183-6.

32. Nitta K, Masakane I, Hanafusa N, Taniguchi M, Hasegawa T, Nakai S, Nakamoto H. Annual dialysis data report 2017, JSDT renal data registry. Ren Replace Ther. 2019:5(1):1-44.

33. Movilli E, Gaggia P, Zubani R, et al. Association between high ultrafiltration rates and mortality in uraemic patients on regular haemodialysis. A 5-year prospective observational multicentre study. Nephrol Dial Transplant. 2007;22:3547-52.

34. Flythe JE, Kimmel SE, Brunelli SM. Rapid fluid removal during dialysis is associated with cardiovascular morbidity and mortality. Kidney Int. 2011;79:250-7.

35. Wong MMY, McCullough KP, Bieber BA, et al. Interdialytic Weight Gain: Trends, Predictors, and Associated Outcomes in the International Dialysis Outcomes and Practice Patterns Study (DOPPS). Am J Kidney Dis. 2017;69(3):367-79.

36. Hirakata H, Nitta K, Inaba M, et al. Japanese Society for Dialysis Therapy Guidelines for Management of Cardiovascular Diseases in Patients on Chronic Hemodialysis. Therapeutic Apheresis and Dialysis. 2012;16(5):387-435.

37. Roumelioti ME, Trietley G, Nolin TD, Ng YH, Xu Z, Alaini A, Argyropoulos CP. Beta-2 microglobulin clearance in high-flux dialysis and convective dialysis modalities: a meta-analysis of published studies. Nephrology Dialysis Transplantation. 2018;33(6):1025-39.

38. Canaud B, Köhler K, Sichart JM, Möller S. Global prevalent use, trends and practices in haemodiafiltration. Nephrol Dial Transplant. 2019:1-10.

39. Kawanishi $\mathrm{H}$. Preferred performance of the high-performance membrane in the case of online hemodiafiltration. Contrib Nephrol. 2011;173:36-43.

40. Storr M, Ward RA. Membrane innovation: closer to native kidneys. Nephrol Dial Transplant. 2018;33:iii22-7.

\section{Publisher's Note}

Springer Nature remains neutral with regard to jurisdictional claims in published maps and institutional affiliations.
Ready to submit your research? Choose BMC and benefit from:

- fast, convenient online submission

- thorough peer review by experienced researchers in your field

- rapid publication on acceptance

- support for research data, including large and complex data types

- gold Open Access which fosters wider collaboration and increased citations

- maximum visibility for your research: over 100M website views per year

At $\mathrm{BMC}$, research is always in progress.

Learn more biomedcentral.com/submissions 